$4^{\text {th }}$ International Meeting on Calcitonin Gene-Related Peptide (CGRP)

TheScientificWorld (2001) 1(S1), 44

ISSN 1532-2246; DOI 10.1100/tsw.2001.429

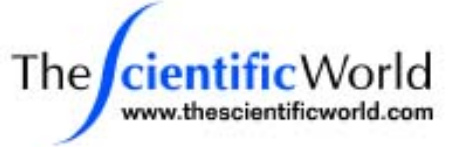

\title{
TRANSGENIC STUDIES ON THE CGRP-RECEPTOR COMPONENT PROTEIN (RCP)
}

\author{
Laila O. Mnayer ${ }^{1}$, Mark I. Rosenblatt ${ }^{1}$, and Ian M. Dickerson ${ }^{1,2}$ \\ ${ }^{1}$ Department of Biochemistry, University of Miami School of Medicine, Miami, FL, USA; \\ ${ }^{2}$ Department of Physiology and Biophysics, University of Miami School of Medicine, Miami, FL, \\ USA
}

The CGRP-receptor component protein (RCP) is a 17-kDa intracellular peripheral membrane protein that is required for signal transduction by the calcitonin receptor-like receptor (CRLR). We have demonstrated that RCP is expressed in tissues and cell lines containing CGRP receptors, and that RCP expression is regulated in parallel with the biological efficacy of CGRP in vivo. We have made stable cell lines which express an antisense RCP CDNA, and have shown that loss of RCP protein correlated with loss of CGRP signal transduction, but not CGRP binding. RCP thus represents a new class of protein required for CGRP-mediated signal transduction. We are generating RCP-deficient mice using homologous recombination to extend these cell culture studies into an in vivo model. These RCP-null mice will have important uses for development of therapeutic strategies targeted at migraine, hypertension, and chronic pain.

To generate RCP-deficient mice by homologous recombination we have constructed a targeting vector that replaces the coding region of the RCP gene with a cassette containing the enhanced green fluorescent protein (EGFP) and the positive selectable marker neomycin phosphotransferase (neo). This cassette is flanked by genomic sequences that we have cloned from mouse genomic DNA. The placement of the EGFP gene under the control of the RCP promoter in recombinant mice offers a unique opportunity to study the expression of RCP in different adult and embryonic tissues, in addition to studying the effects of deletion of RCP on CGRP physiology. This work was supported in part by NIH DK52328 (IMD). 

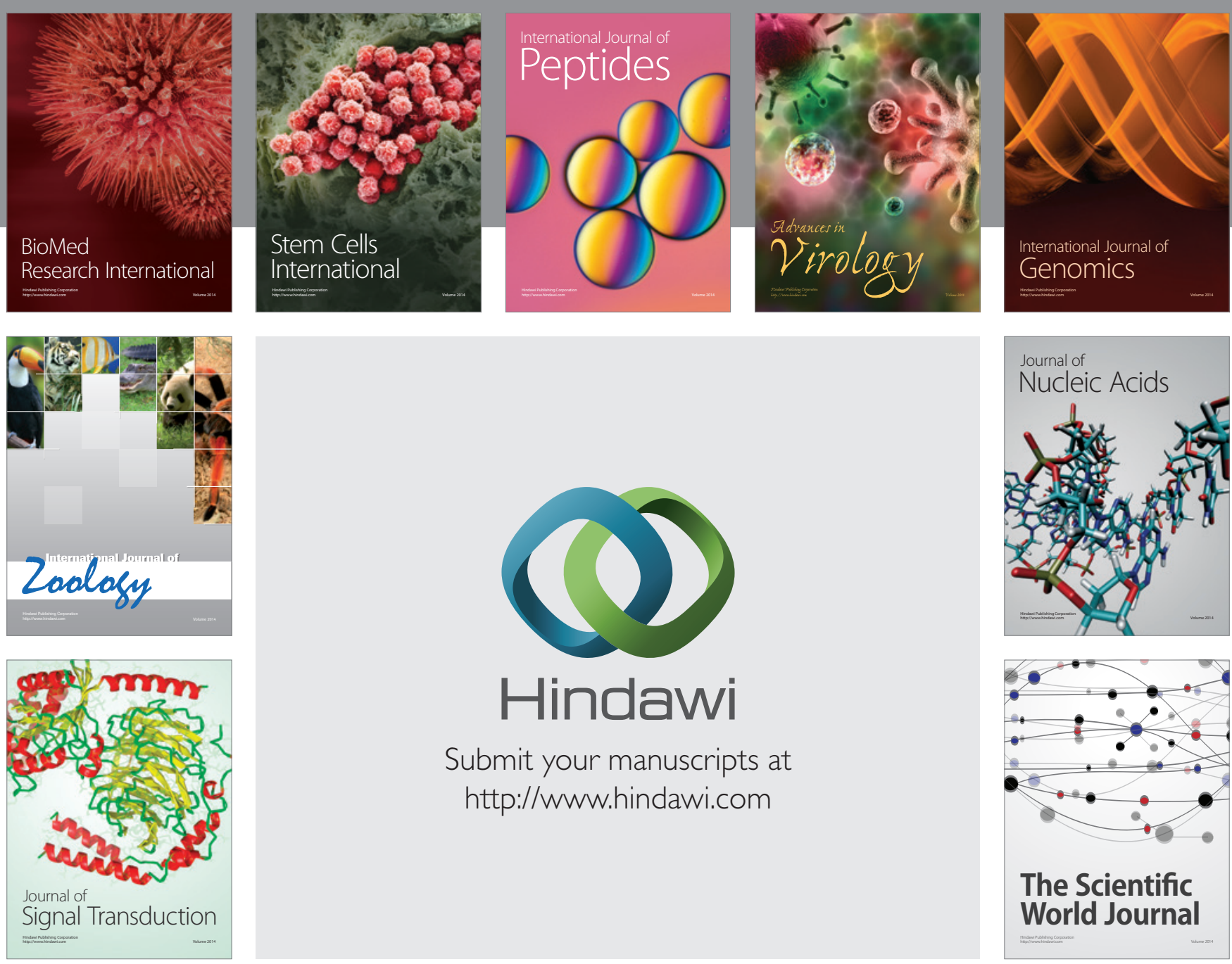

Submit your manuscripts at

http://www.hindawi.com
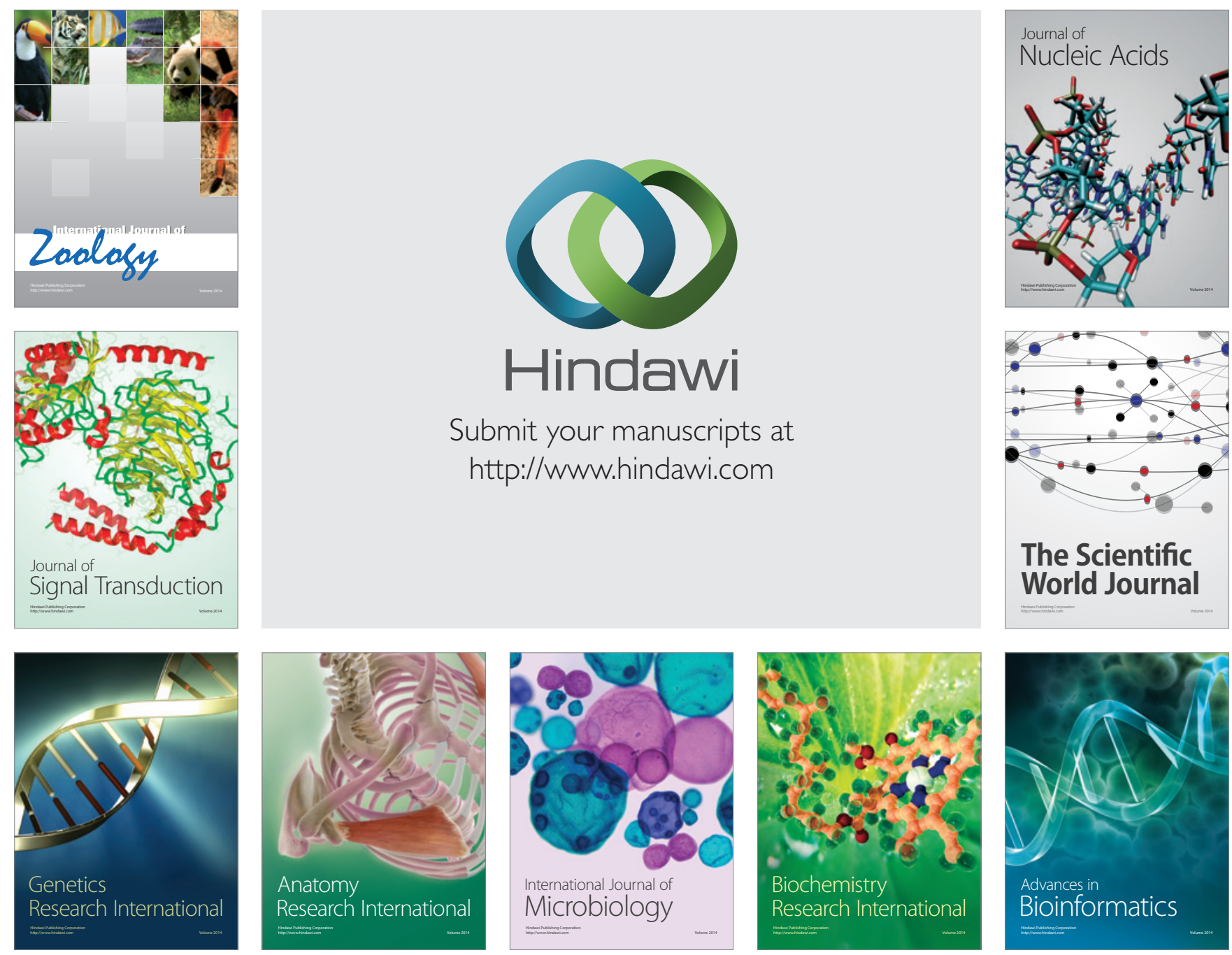

The Scientific World Journal
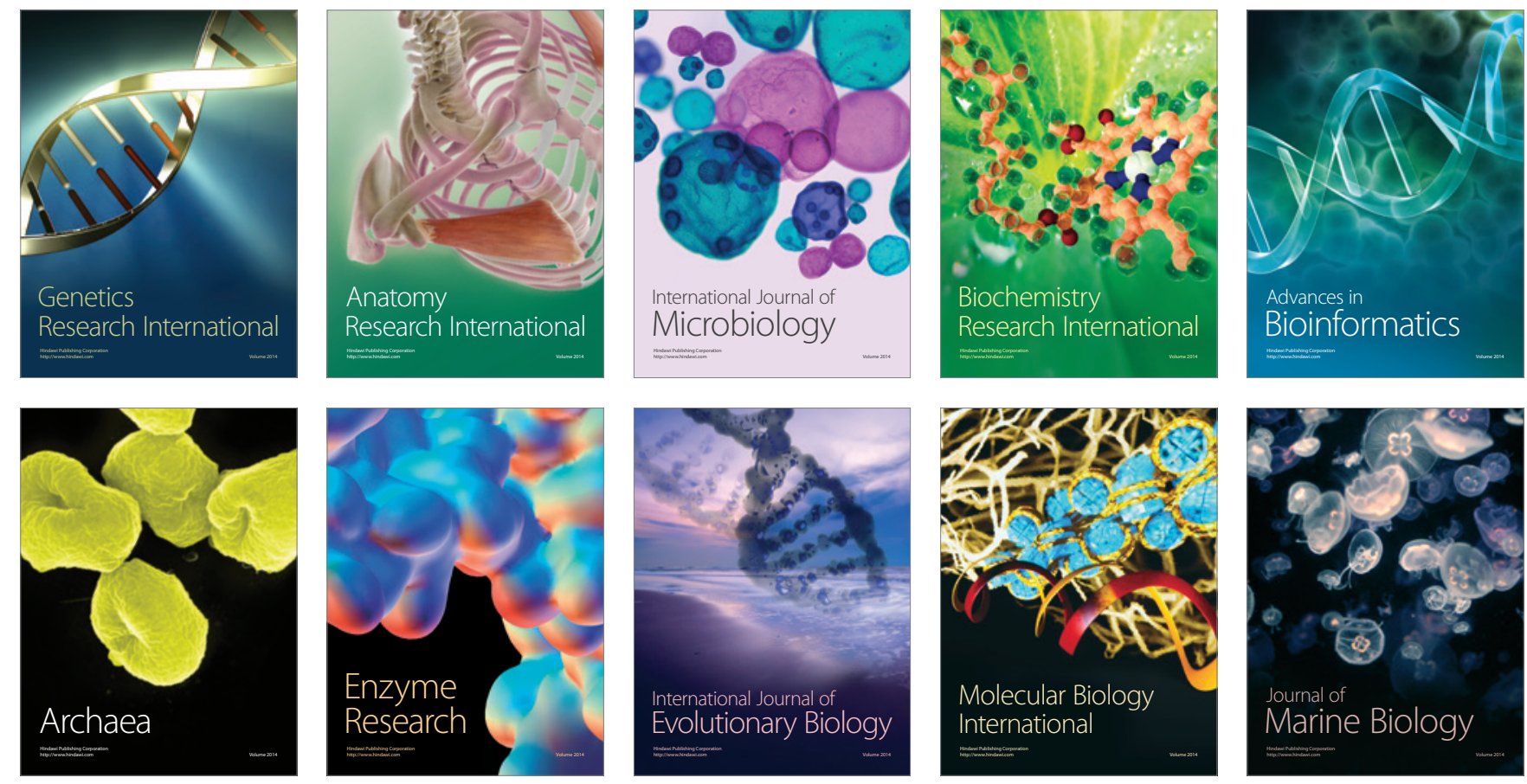